Annales de la Société Entomologique de France, 2019, 55 (6), pp.497-508.

10.1080/00379271.2019.168818

\title{
Diversity and temporal variations of the Auchenorrhyncha fauna in the Ajaccio region (France, Corsica)
}

Jérôme Albre $^{a *}$ and Marc Gibernau ${ }^{a}$

${ }^{a}$ University of Corsica Pascal Paoli-CNRS, UMR 6134 SPE, Equipe Chimie et Biomasse, Route des Sanguinaires, 20000 Ajaccio, France.

\begin{abstract}
During a one-year survey of the Auchenorrhyncha fauna in a maquis habitat of the Ajaccio region (Corsica), 37 species were listed including 3 alien species recorded in Europe in the last decades. The standard $658 \mathrm{bp}$ mitochondrial COI barcode was obtained for 32 species, including 14 species never previously barcoded. Neighbor-Joining analyses confirmed the monophyly for all of them. However, comparisons with available sequences from the mainland Europe showed that 4 species presented a significant intraspecific divergence (>3\%) whereas a reduced interspecific divergence was found for another set of species. Complementary studies are therefore necessary to better assess their taxonomic levels. Three species - Euscelis lineolata (Cicadellidae), Philaenus spumarius (Aphrophoridae) and Latilica maculipes (Issidae) - account for up to $74.3 \%$ of the total insects collected. Although phylogenetic and taxonomic interpretations using restricted sampling and $\mathrm{COI}$ sequences alone are not robust, the proportion of new sequences highlight the global lack of knowledge about the Auchenorrhyncha as a whole and the potentially presence of cryptic taxa in different clades.
\end{abstract}

\footnotetext{
* Corresponding author. Email: albre_j@univ-corse.fr.
} 


\section{Résumé. Diversité et variations temporelles de la faune Auchenorrhynque}

dans la région Ajacienne (Corse). Un suivi de la faune Auchenorrhynque dans un maquis de la région d'Ajaccio (Corse) effectué durant une année a permis l'enregistrement de 37 espèces, incluant 3 espèces introduites en Europe ces dernières décennies. Le fragment standard de $658 \mathrm{pb}$ du gene mitochondrial COI utilisé pour le barcoding a été obtenu pour 32 espèces, parmi lesquelles 14 ont été nouvellement séquencées. La monophylie de chacune des espèces a été confirmée par les analyses en Neighbor-Joining. Dans le cas de 4 espèces, les séquences obtenues pour les spécimens de Corse présentent une divergence intraspécifique significative (>3\%) par rapport aux séquences de spécimens d'Europe continentale; au contraire, une faible divergence interspécifique a été mise en évidence pour un autre groupe d'espèces. Des études complémentaires sont cependant nécessaires afin de clarifier le statut taxonomique de chacune de ces entités. Trois espèces - Euscelis lineolata (Cicadellidae), Philaenus spumarius (Aphrophoridae) et Latilica maculipes (Issidae) - représentent à elles-seules $74.3 \%$ des insectes collectés. Bien que les interprétations phylogénétiques et taxonomiques basées sur un échantillonage limité et sur un unique gène mitochondrial ne sont pas robustes, la proportion de séquences nouvelles et la présence d'entités génétiques divergentes mettent en évidence le manque global de connaissances concernant les Auchenorrhynques.

Key words: Philaenus spumarius; abundance; maquis; COI barcode; taxon divergence. 


\section{Introduction}

Composed of over 40.000 described species worldwide, the Auchenorrhyncha (Hemiptera) suborder is represented by the Cercopoidea (spittlebugs), Cicadoidea (cicadas), Membracoidea (leafhoppers and treehoppers), and Fulgoroidea (planthoppers) superfamilies (Dietrich 2009). All members of this ubiquitous group are sap-feeders, each species usually exploiting a specific source of sap. Actually, xylem feeders are mainly represented by spittlebug, cicada and Cicadellinae (Membracoidea, Cicadellidae) species, while treehopper, planthopper and most of the leafhopper species are usually considered as phloem feeders. The specialized Typhlocibinae subfamily (Membracoidea, Cicadellidae) is composed of mesophyll sap feeder species. Several Auchenorrhyncha species can injure the plant and/or inoculate pathogens (bacteria, fungus or viruses) while they are feeding on it and are thus considered as pests (Nielson 1968; Dietrich 2009; 2013).

The European diversity of Auchenorrhyncha is relatively incomplete, with local or national species lists produced only for France (Ribaut 1952; Della Giustina 1989; Puissant 2006), Germany (Nickel 2003) and Italy (Guglielmino et al. 2000; Guglielmino et al. 2005; Mazzoni 2005; D’Urso \& Mifsud 2012; Guglielmino et al. 2015). In Corsica, only two published studies concern the Cicadellidae (Della Giustina \& Bonfils 1978) and the cicadas (Puissant \& Sueur 2001). More recently, a one-week field mission recording the Auchenorrhyncha diversity was also performed in Corsica (Chauvel et al. 2015). Despites the high diversity of the Auchenorrhyncha suborder, this group is as a whole poorly known. In the scope of studying the eco-ethology and the abundance of the potential insect vectors of the plant pathogen Xylella fastidiosa Wells et al. 1987 in Corsica, we performed a one-year long survey of the Auchenorrhyncha diversity in a maquis habitat of the Ajaccio region. This study will also contribute to the International Barcode of Life (iBOL) project by sequencing a fragment of the Cytochrome Oxidase subunit I (COI) of all the collected species. 
In this paper, we first discuss the species identification and delimitation based on morphological and COI sequences data. Then, we will present the diversity and abundance of the Auchenorrhyncha fauna in South West of Corsica (Ajaccio), but also the annual temporal variations of the most abundant species.

\section{Materials and methods}

\section{Sample collection}

From March 2017 to March 2018, a survey of the Auchenorrhyncha fauna was performed in the Ajaccio region (Corsica). Insects from the herbaceous and shrub strata were collected once a week in two close sites (GPS coordinates: 41 ${ }^{\circ} 54^{\prime} 49.9^{\prime \prime} \mathrm{N} 8^{\circ} 39^{\prime} 18.4^{\prime \prime} \mathrm{E}$ and $41^{\circ} 55^{\prime} 18.9^{\prime \prime} \mathrm{N} 8^{\circ} 38^{\prime} 46.3 " \mathrm{E}$, respectively) using a sweep-net and stored in $75 \%$ ethanol. The mediterranean vegetation at the studied sites was dominated by Pistacia lentiscus L. 1753, Cytisus laniger (Desfontaines) De Candolle 1805, Cistus monspeliensis L. 1753, Olea europaea var sylvestris (Miller) Lehr 1779, Arbutus unedo L. 1753, Phillyrea angustifolia L. 1753 and Myrtus communis L. 1753. Cicadas were not considered in this survey, since this group, living in the canopy of the trees, requires a dedicated study.

\section{Morphological identifications}

Most of the adult specimens were identified to species level by the examination of the male appendages, based on the identification keys of Ribaut (1952) and Della Giustina (1989). Identifications were also confirmed by three international specialists, Dmitry Dimitriev (Cicadellidae), Thierry Bourgoin (Issidae and Tettigometridae) and Adeline Soulier (Aphrophoridae). The identification of the nymphs was usually more difficult using traditional morphological methods. Consequently, some specimens of the different nymph morphotypes were collected alive and reared to the adult stage. Specimens collected in the herbaceous or 
shrub strata were reared on Poa аппиа L. 1753 (Poaceae) or A. unedo (Ericaceae), respectively. While $P$. annua plants were transplanted in pots, we used cuttings of $A$. unedo placed in waterfilled jars. In all cases, plants were bagged to avoid insects to escape. Voucher specimens of each species were deposited to the Office de l'Environnement de la Corse (OCIC, Corte). Similarly, Issidae, Tettigometridae and Aphrophoridae specimens are available at Thierry Bourgoin's laboratory (MNHN, Paris) and Cicadellidae at Dmitry Dimitriev's laboratory (Illinois Natural History Survey, USA).

\section{Barcoding}

We also adopted a molecular approach, by sequencing a partial Cytochrome Oxidase subunit I (COI) fragment of the species collected in the studied sites or neighbouring areas. Genomic DNA was extracted from the abdomen of the insects using the E.Z.N.A. Insect DNA Kit (Omega Bio-tek). A fragment of the COI gene (658 bp) was amplified by PCR using the M13-tailed primers LCO1490puc_t1 (TGTAAAACGACGGCCAGTTTTCAACWAATCATAAAGATATTGG) and HCO2198puc_t1 (CAGGAAACAGCTATGACTAAACTTCWGGRTGWCCAAARAATCA) (Cruaud et al. 2010; Atiama et al. 2017). Amplifications were performed using the PCR Master Mix (2X) (Thermo Scientific) in a $50 \mu 1$ reaction containing $25 \mu 1$ of PCR Master Mix, 0.25 $\mu \mathrm{M}$ of each primer and $250 \mathrm{ng}$ of DNA template. Thermocycling conditions were: an initial denaturation at $94^{\circ} \mathrm{C}$ for $3 \mathrm{~min}$, followed by 5 cycles of $30 \mathrm{~s}$ denaturation at $94^{\circ} \mathrm{C}, 30 \mathrm{~s}$ annealing at $45^{\circ} \mathrm{C}, 1$ min elongation at $72^{\circ} \mathrm{C}$ and 35 cycles of 1 min denaturation at $94^{\circ} \mathrm{C}, 1$ min annealing at $51^{\circ} \mathrm{C}, 1$ min elongation at $72^{\circ} \mathrm{C}$, and a terminal elongation at $72^{\circ} \mathrm{C}$ for $10 \mathrm{~min}$. PCR products were sequenced by BIOFIDAL (France) using the primers M13F (TGTAAAACGACGGCCAGT) and M13R (CAGGAAACAGCTATGAC) in separate reactions. 
Sequences were deposited in the online databases GenBank and BOLD. Most of the barcode sequences obtained were new for science, and thus relevant molecular identifications to species level were often not possible. Consequently, we selected COI sequences of related taxa available on BOLD or GenBank for the specimens for which we generated sequences for comparative purposes and clade affiliations. GenBank accession numbers and BOLD sequence pages are available in the Appendix Table 1. Alignments and distance analyses were performed using MEGA X (Kumar et al. 2018) and Taxon DNA (Meier et al. 2006), respectively. Neighbor-Joining phylogenetic inferences were performed using the Kimura's 2 Parameter (K2P) distance model in MEGA X (Kumar et al. 2018).

\section{Results \& Discussion}

Between March 2017 and March 2018, a total of 2562 specimens have been collected in the studied area (Table 1), including 1364 adults and 1198 nymphs, corresponding to 38 and 11 morphotypes, respectively. Rearing experiments of the nymphs allowed us to identify each of the distinct morphotypes after development completion. They all corresponded to adults already collected in the study area. However, adults belonging to two distinct Cicadellidae species, namely Synophropsis lauri (Horváth 1897) and Placotettix taeniatifrons (Kirschbaum 1868), were obtained for one single nymph morphotype.

The COI sequences (658 bp) were obtained for 65 adult specimens, representing 33 out of the 38 morphotypes (Table 1). Sequencing failed for 5 morphotypes, including 4 Cicadellidae Jikradia cf. olitoria (Say 1830) Orientus ishidae (Matsumura 1902), Opsius stactogalus Fieber 1866 and Austroagallia sinuata (Mulsant \& Rey 1855) - and the Tettigometridae Tettigometra laeta Herrich-Schäffer 1835. In summary, $42 \%$ of the obtained BOLD Identification Numbers (BIN) were new, 23\% led to new species identifications (i.e. BINs with no species name), 19\% matched identified sequences and $16 \%$ were incongruent (see below). Neighbor-Joining (NJ) 
reconstructions of the different families (Appendix Figure 1A-C) revealed the presence of 32 distinct species, thus confirming most of the initial morphotypes designations. The sequences of 14 of them are new for science and correspond to species for which no COI barcode was available in the online databases. BOLD systems thus created new BINs for 13 of these genetic entities (Table 1). No BIN was assigned to the last, namely Tettigometra virescens (Panzer 1799) (Tettigometridae), because its sequence did not fulfill the quality requirements imposed by the BOLD systems. On the other hand, 13 genetic entities corresponded to sequences already available on the online databases. While 6 of them were identified to the species level and corresponded to our initial identifications, the other sequences corresponded to non-identified species. However, the low genetic divergence within their respective clade $(0 \%-1.2 \%)$ leads us to think that these unnamed sequences could likely be conspecific with our named specimens. The NJ reconstruction of the Tettigometridae family (Appendix Figure 1C) revealed that two distinct morphotypes belonging to the genus Tettigometra Latreille 1804 (dark and brachypterous form vs. orange and winged form) were conspecific and corresponded to distinct forms of T. impressifrons, thus confirming the morphological identifications by T. Bourgoin. The immature stages of winged insects are characterized be reduced wings and thus are not able to fly. However, in the case of $T$. impressifrons, matings have been observed in several occasions between brachypterous specimens (Albre, pers. obs.), suggesting they corresponded to adult specimens. Such a wing dimorphism is common in aphids and has been associated to different reproductive strategies. Actually, winged forms correspond to dispersing specimens adapted for the colonization of new sites, while wingless forms correspond to non-dispersing specimens specialized for reproduction (Braendle et al. 2006). Finally, the sequences of 5 taxa presented some barcoding incongruences compared to sequences present in the databases (Figure 1; Appendix Table 2). The sequences of the specimens identified as Agalmatium flavescens (Olivier 1791) (Issidae) presented significant divergences compared to the sequences 
of supposed conspecific taxa (5.9\%). Congruently, BOLD algorithms attributed a distinct BIN to these specimens, suggesting they could correspond to a distinct species. The sequence of the unique Corsican specimen identified as Aphrodes makarovi Zachvatkin 1948 (Cicadellidae, Aphrodinae) is identical to a specimen collected in British Columbia (Canada; Appendix Table 2). However, these two specimens present an important genetic divergence compared to the majority of the A. makarovi (5.9-6.8\%) sequenced from North America and Northern Europe and to the other species of Aphrodes Curtis 1833 (5.7-7.6\%); they also present a specific BIN (Appendix Table 2). Although the identification of Aphrodes specimens is not possible using morphological characters alone, acoustic and molecular (COI barcoding) identifications of the commonest European species resulted to congruent results (Bluemel et al. 2014). According to these authors, these taxa presented between $4.2 \%$ and $7.0 \%$ of genetic divergence, which is congruent with our estimations (4.2-7.6\%). Consequently, the genetic divergence of the Corsican (and Canadian) specimen compared to any of the other Aphrodes species suggests that it could represent a distinct lineage (Appendix Table 2). However, complementary studies, including acoustic, other molecular approaches, and a more important sampling effort, are necessary to better characterize this taxa. The two female specimens tentatively identified as Anoscopus assimilis (Signoret 1879) (Cicadellidae, Aphrodinae) appeared to belong to a clade including two additional species, A. albifrons (L. 1758) and A. limicola (Edwards 1908) (0.3$2.1 \%$ divergence). However, morphological identification is not possible for the females, and very challenging for the males. Consequently, identification errors can't be excluded, concerning the Corsican specimens deposited in the reference collections or in the online databases. However, an integrative review of the genus Anoscopus Kirschbaum 1868, similar to Bluemel et al. (2014) study on Aphrodes combining molecular, morphological and acoustic approaches is necessary to better characterize the different taxa. The sequences of Aphrophora alni (Fallén 1805) (Aphrophoridae) presented between 2.4\% and 4.1\% divergence (Appendix 
Table 2), which is in the range of the $3 \%$ arbitrary threshold usually admitted to distinguish conspecific from non-conspecific animal taxa based on COI barcodes (Godfray et al. 2005). However, four distinct BINs, corresponding to four distinct genetic lineages on the NJ tree (Appendix Figure 1B), have been assigned by BOLD systems to the different existing sequences attributed to $A$. alni. The unique Corsican specimen successfully sequenced, for whom a new BIN has been created, appeared to be the most divergent taxa (3.7-4.2\%). While specimens from North America and Russia correspond to a specific clade, the situation appears to be more complex for the Western European ones, which are divided into three distinct groups. Complementary studies are thus necessary to better understand the systematics and genetic structure of this taxon. The sequence of Agalmatium bilobum (Fieber 1877) (Issidae) from Corsica also presented a genetic divergence close to the $3 \%$ threshold $(2.9 \%)$ with the available sequence from Lebanon. However, with only a single specimen available in both cases, further consideration will be avoided.

The barcoding approach allowed confirming the presence of 32 different Auchenorrhyncha species in our sampled community. When considering the 5 well distinct morphotypes for which no sequence was obtained, it can be assumed that a total of 37 species have been recorded during the one-year survey. The Cicadellidae was the most represented family (60,5\% of the collected specimens; 27 species), followed by the Aphrophoridae (22.2\%; 3 species), the Issidae (15.6\%; 4 species) and the Tettigometridae (1.8\%; 3 species). To our knowledge, 7 species are new records for Corsica. Four of them - Latilica maculipes (Melichar 1906), Agalmatium flavescens, A. bilobum and Issus muscaeformis (Schrank 1781) - belong to the Issidae family and are native European species. In return, none of the Issidae species supposed to be present in Corsica (Della Giustina \& Bonfils 1978; Gnezdilov et al. 2014) was found during the survey. Latilica maculipes, one of the most abundant Auchenorrhyncha 
species in the Ajaccio region, has never been recorded in Corsica. The three others species are alien Cicadellidae coming from the Americas (Jikradia cf. olitoria) or the Oriental region (Hishimonus hamatus Kuoh 1976 and Orientus ishidae); however one single specimen of each of these leafhopper species has been observed. The first European occurrence of a Jikradia Nielson species (J. olitoria) was recorded in Italy in 2013 (Nielson et al. 2014); while this species was suspected in the SW of France from 2016 (Insecte.org 2016), it is up-to-date the only observation validated in Europe. The two Oriental leafhopper species $O$. ishidae and $H$. hamatus have already been detected in Europe, in Italy since 1998 (Guglielmino 2005) and in Slovenia since 2012 (Seljak 2013), respectively. Since their first observation, both species expanded their distribution range and can now be found in most of the West-European countries (Trivellone et al. 2015; Klejdysz et al. 2017). These three alien species or related ones are known to be vectors of plant pathogens diseases, particularly phytoplasmas. These organisms are close to the bacteria but with no wall and no nucleus, develop in the phloem of the plants and need phloem feeder insects (mainly Auchenorrhyncha) for dispersal (Weintraub \& Beanland 2006). Phytoplasmas are known to be responsible for several hundreds of plant diseases worldwide (Firrao et al. 2005). The leafhopper J. olitoria is a potential vector of a phytoplasma associated with the North American Grapevine Yellows, a lethal disease of grapevines in the USA (Lenzi et al. 2019). Similarly, it has been demonstrated in Italy that the Oriental species $O$. ishidae is a vector of the phytoplasma associated with the Flavescence Doree, which is one of the most serious diseases affecting European vineyards (Lessio et al. 2016). Species related to H. hamatus, such as H. phycitis (Distant 1908) and H. sellatus (Uhler 1896), are vectors of phytoplasmas affecting among others Citrus aurantiifolia (Christmann) Swingle 1913 (Witches' broom) in China, Solanum melongena L. 1753 (Little leaf of eggplant) in India and Ziziphus jujuba Miller 1768 (Jujube witches' broom) in eastern Asia (Kusunoki et al. 2002; Hao et al. 2015). Moreover, it has been demonstrated that H. sellatus can transmit 
different phytoplasmas and thus can be the vector of different diseases (Kusunoki et al. 2002). H. phycitis is considered as a potential threat and is regarded as Union quarantine pest by the European Food Safety Authority (EFSA 2017).

Three out of the 37 recorded species represented up to $74.3 \%$ of the total number of the collected adult insects (Figure 2): Euscelis lineolata Brullé 1832 (Cicadellidae; 39.3\%), Philaenus spumarius (L. 1758) (Aphrophoridae; 21.7\%) and Latilica maculipes (Issidae; 13.3\%). Among the nymphs, the more represented species were L. maculipes $(32.6 \%)$, E. lineolata (Cicadellidae; 19.2\%) and Anoplotettix fuscovenosus (Ferrari 1882) (Cicadellidae; $18.5 \%$ ). Even if abundantly present on the studied sites, the nymphs of $P$. spumarius, developing within characteristic foams mainly on Cistus monspeliensis L. 1753, have voluntarily not been collected, since their identification was not problematic.

In the Ajaccio region, E. lineolata was represented by two distinct morphotypes, with differences in the general coloration of the adults and in the sexual appendages of the males (Ribaut 1952). Their conspecificity was confirmed by COI sequences (Appendix Figure 1A). The first morphotype, E. lineolata f. stictopterus Flor 1861, corresponded to the winter generation, while the second one, E. lineolata f. lineolata, was found in May and later in September. The later morphotype disappeared from the survey during the driest weeks of summer, from June to the mid-August (Figure 3). Nymphs were collected from May to June (f. lineolata) and from November to February (f. stictopterus). Both adults and larvae develop mainly on grasses, feeding on the phloem of the plants. This leafhopper species is predominantly recorded from Western Europe (Müller, 1979). According to the environmental conditions, this species can present several generations each year with up to seven distinct transitional morphs, formerly considered as different species. Interestingly, this variation also concerns the sexual appendages, with the aedeagus of the males forming eunomic rows of 
morphs (Müller 1954; 1979). In most animals and particularly in insects, such structures are usually highly conserved for successful mating with conspecific females, and thus constitute powerful taxonomic characters. The sexual appendages are more problematic to interprate in the case of E. lineolata and in the related species E. incisa and E. alsia Ribaut (Müller 1979). E. lineolata is a vector of phytoplasmas responsible for the green-petal disease and the Clover phyllody, affecting mainly Asteraceae and Trifolium L. 1753 species, respectively (Weintraub \& Beanland 2006).

The meadow spittlebug $P$. spumarius is a common species that can be found in most of the Holarctic region, in Europe, Asia and in the Americas. With up to 50 distinct morphs, formerly considered as distinct species, this highly polymorphic species was the aim of many studies from taxonomists and geneticists (Drosopoulos et al. 2010). In the studied area, adult specimens were first observed in spring and later in autumn/winter (Figure 3). The first appearance period corresponded to the emergence of the adults, while the second one corresponds to the mating and egg laying period. Extremely few adults were collected between these two periods, which corresponds to the warmest and driest weeks of summer. Actually, adults survive this critical period by aestivating in shrubs and trees (Drosopoulos et al. 2010). However, when environmental conditions are more suitable, such as at higher altitudes and/or latitudes, aestivation is not necessary and adults can be observed even in summer (Drosopoulos 2003). The nymphs of $P$. spumarius, not very mobile contrary to the adults, develop mainly on grasses and shrub, feeding on the xylem of their host plants (Yurtsever 2000). In Europe, P. spumarius is considered as the main vector of Xylella fastidiosa (Xanthomonadaceae), one of the most dangerous plant bacteria in the world (Saponari et al. 2014; Cornara et al. 2017), with up to 300 recorded host plants (Redak et al. 2004). X. fastidiosa is responsible for the Pierce's disease, one of the most serious diseases affecting American vineyards. It is also responsible for economic damages on diverse agricultural or ornamental crops among which Citrus L. 1753, 
Prunus L. 1753, coffee, oleander (Redak et al. 2004) and, more recently, olive trees (EPPO 2013).

The planthopper L. maculipes is one of the most common species in the studied area. But interestingly, it also constitutes a species new for Corsica (Della Giustina \& Bonfils 1978; Gnezdilov et al. 2014). Adults and nymphs, both highly mobiles, can be found almost exclusively on shrubs and trees, mainly from May to September (Figure 3). Planthoppers are considered as phloem feeders (Wang et al. 2016); however, nothing is known about the ecology of L. maculipes and about the ecology of the Issidae family as a whole.

\section{Conclusion}

A one-year survey of the Auchenorrhyncha fauna in the Ajaccio region allowed recording the presence of 37 species, among which 7 appear to be new for Corsica. Three of them are alien species, recorded in Europe in the last decades. Three species - Euscelis lineolata (Cicadellidae), Philaenus spumarius (Aphrophoridae) and Latilica maculipes (Issidae) accounted for up to $74.3 \%$ of the total insects collected. Barcoding of the COI region has been successfully performed for 32 species. For 14 of them, the produced sequences are new for science and identifications are provided for 7 unnamed taxa already present in the Genbank or BOLD online databases. Moreover, Neighbor-Joining analyses revealed incongruences for 5 taxa; however, complementary studies are necessary to better assess their taxonomic level. Although phylogenetic and taxonomic interpretations using restricted sampling and COI sequences alone are not robust, the proportion of new and/or suspicious sequences highlight the global lack of knowledge about the Auchenorrhyncha as a whole and the potentially presence of cryptic taxa in different clades. 


\section{Acknowledgements}

Financial supports were provided by the Research Program "Eco-epidemiology of Xylella fastidiosa in Corsica" (Collectivité de Corse - Office de l'Environnement) and the University of Corsica through its post-doctoral program. The authors wish aslot to thank Thierry Bourgoin and Adeline Soulier (MNHN, Paris), and Dmitry Dimitriev (Illinois Natural History Survey, USA) for helping in the specimen identifications. 


\section{References}

Atiama M, Ramage T, Jacquot M, Sadeyen JAM, Delatte H, Deguine J-P. 2017. Characterization of mirid assemblages (Heteroptera, Miridae) in mango orchards in Reunion Island and implementation of identification and recognition tools. Fruits. 72: 382-390.

Bluemel JK, Derlink M, Pavlovčič P, Russo I-RM, Andrew King R, Corbett E, Sherrard-Smith E, Blejec A, Wilson MR, Stewart AJA, Symondson WOC, Virant-Doberlet M. 2014. Integrating vibrational signals, mitochondrial DNA and morphology for species determination in the genus Aphrodes (Hemiptera: Cicadellidae). Systematic Entomology. 39: 304-324.

Braendle C, Davis GK, Brisson JA, Stern DL. 2006. Wing dimorphism in aphids. Heredity. 97: 192-199.

Chauvel G, Cruaud A, Legendre B, Germain J-F, Rasplus J-Y. 2015. Mission d'expertise sur Xylella fastidiosa en Corse (3 au 11 août 2015). Ministère de l'agriculture, de l'agroalimentaire et de la forêt (DGAL), Paris, France.

Cornara D, Saponari M, Zeilinger AR, de Stradis A, Boscia D, Loconsole G, Bosco D, Martelli GP, Almeida RPP, Porcelli F. 2017. Spittlebugs as vectors of Xylella fastidiosa in olive orchards in Italy. Journal of Pest Science. 90: 521-530.

Cruaud A, Jabbour-Zahab R, Genson G, Cruaud C, Couloux A, Kjellberg F, van Noort S, Rasplus J-Y. 2010. Laying the foundations for a new classification of Agaonidae (Hymenoptera: Chalcidoidea), a multilocus phylogenetic approach. Cladistics. 26: 359387.

D’Urso V, Mifsud D. 2012. A preliminary account of the Auchenorrhyncha of the Maltese Islands (Hemiptera). Bulletin of the Entomological Society of Malta. 5: 57-72.

Della Giustina W. 1989. Homoptères Cicadellidae (supplément). Paris: INRA.

Della Giustina W, Bonfils J. 1978. Contribution à l'étude des Homoptères Auchénorhynques (Homoptera, Auchenorrhyncha). Bulletin de la Société des Sciences Historiques et Naturelles de la Corse. 2/3: 93-112.

Dietrich CH. 2009. Auchenorrhyncha (Cicadas, Spittlebugs, Leafhoppers, Treehoppers, and Planthoppers). In: Resh VH, Cardé RT (eds). Encyclopedia of insects (second edition). San Diego (CA): Academic Press, Elsevier Science; p. 56-64. 
Dietrich CH. 2013. Overview of the phylogeny, taxonomy and diversity of the leafhopper (Hemiptera: Auchenorrhyncha: Cicadomorpha: Membracoidea: Cicadellidae) vectors of plant pathogens In: Chang C-J, Lee C-Y, Shih H-T (eds). Proceedings of the 2013 International Symposium on Insect Vectors and Insect-Borne Diseases. Tai Chung, Taiwan; p. 47-69.

Drosopoulos S. 2003. New data on the nature and origin of colour polymorphism in the spittlebug genus Philaenus (Hemiptera: Aphorophoridae). Annales de la Société Entomologique de France (N.S.). 39: 31-42.

Drosopoulos S, Maryańska-Nadachowska A, Kuznetsova VG. 2010. The Mediterranean: area of origin of polymorphism and speciation in the spittlebug Philaenus (Hemiptera, Aphrophoridae). Zoosystematics and Evolution. 86: 125-128.

EFSA. 2017. Pest categorisation of Hishimonus phycitis. EFSA Journal. 15: 5037.

EPPO - European and Mediterranean Plant Protection Organization 2013. First report of Xylella fastidiosa in Italy. Reporting Service 09: 2013/184.

Firrao G, Gibb KS, Strten C. 2005. Short taxonomic guide to the genus 'Candidatus Phytoplasma'. Journal of Plant Pathology. 87: 249-263.

Gnezdilov VM, Holzinger WE, Wilson MR. 2014. The Western Palaearctic Issidae (Hemiptera, Fulgoroidea): an illustrated checklist and key to genera and subgenera. Proceedings of the Zoological Institute RAS. 318: 1-124.

Godfray C, Meyer CP, Paulay G. 2005. DNA barcoding: error rates based on comprehensive sampling. - PLoS Biology. 3: e422, 2229-2238.

Guglielmino A. 2005. Observations on the genus Orientus (Rhynchota Cicadomorpha Cicadellidae) and description of a new species: O. amurensis n. sp. from Russia (Amur Region and Maritime Territory) and China (Liaoning Province). Marburger Entomologische Publikationen. 3: 99-110.

Guglielmino A, Bückle C, Remane R. 2005. Contribution to the knowledge of the Auchenorrhyncha fauna of Central Italy (Hemiptera, Fulgoromorpha and Cicadomorpha). Marburger Entomologische Publikationen. 3: 13-98.

Guglielmino A, D'Urso V, Alma A. 2000. Auchenorrhyncha (Insecta, Homoptera) from Sardinia (Italy): a faunistic, ecological and zoogeographical contribution. Deutsche Entomologische Zeitschrift. 47: 161-172. 
Guglielmino A, Modola F, Scarici E, Speranza S, Bückle C. 2015. The Auchenorrhyncha fauna (Insecta, Hemiptera) of Villa Lante, Bagnaia (Italy): a study of an urban ecosystem Bulletin of Insectology. 68: 239-253.

Hao S, Wang H, Tao W, Wang J, Zhang Z, Zhang Q, Zhang M, Guo L, Shi X. 2015. MultiplexPCR for identification of two species in genus Hishimonus (Hemiptera: Cicadellidae) in jujube orchards. Journal of Economic Entomology. 108: 2443-2449.

Insecte.org 2016. [Jikradia olitoria] Cicadellidae http://www.insecte.org/forum/viewtopic.php?f=12\&t=160897\&hilit=jikradia\&sid=fe3 9f4e3d2cca48f01e7771b05fb7bbb (last accessed 03.VI.2019)

Klejdysz T, Zwolińska A, Walczak M, Kobiałka M. 2017. The first record of a potential pest Orientus ishidae (Matsumura, 1902) (Hemiptera: Cicadellidae) in Poland. Journal of Plant Protection Research. 57: 107-112.

Kumar S, Stecher G, Li M, Knyaz C, Tamura K, Battistuzzi FU. 2018. MEGA X: Molecular Evolutionary Genetics Analysis across computing platforms. Molecular Biology and Evolution. 35: 1547-1549.

Kusunoki M, Shiomi T, Kobayashi M, Okudaira T, Ohashi A, Nohira T. 2002. A leafhopper (Hishimonus sellatus) transmits phylogenetically distant phytoplasmas: Rhus yellows and Hovenia witches' broom phytoplasma. Journal of General Plant Pathology. 68: 147154.

Lenzi P, Stoepler TM, McHenry DJ, Davis RE, Wolf TK. 2019. Jikradia olitoria ([Hemiptera]:[Cicadellidae]) transmits the sequevar NAGYIII $\beta$ phytoplasma strain associated with North American Grapevine Yellows in artificial feeding assays. Journal of Insect Science. 19: 1-10.

Lessio F, Picciau L, Gonella E, Mandrioli M, Tota F, Alma A. 2016. The mosaic leafhopper Orientus ishidae: host plants, spatial distribution, infectivity, and transmission of $16 \mathrm{SrV}$ phytoplasmas to vines. Bulletin of Insectology. 69: 277-289.

Mazzoni V. 2005. Contribution to the knowledge of the Auchenorrhyncha (Hemiptera Fulgoromorpha and Cicadomorpha) of Tuscany (Italy). Redia. 88: 85-102.

Meier R, Shiyang K, Vaidya G, Ng PKL, Hedin M. 2006. DNA barcoding and taxonomy in Diptera: a tale of high intraspecific variability and low identification success. Systematic Biology. 55: 715-728.

Müller HJ. 1954. Der Saisondimorphismus bei Zikaden der Gattung Euscelis Brullé. Beiträge zur Entomologie. 4: 1-56. 
Müller HJ. 1979. Effects of photoperiod and temperature on leafhopper vectors. In: Maramorosch K, Harris KF (eds). Leafhopper vectors and plant disease agents. New York: Academic Press; p. 29-94.

Nickel H. 2003. The leafhoppers and planthoppers of Germany (Hemiptera, Auchenorrhyncha): patterns and strategies in a highly diverse group of phytophagous insects. Sofia: Pensoft Publishers.

Nielson MW. 1968. The leafhopper vectors of phytopathogenic viruses (Homoptera, Cicadellidae). Taxonomy, biology and virus transmission. Washington: United States Department of Agriculture.

Nielson MW, Zack RS, Poggi F, Nickel H. 2014. New leafhopper species of Jikradia from Mesoamerica with new records, revised key to species, distribution, origin, and checklist (Hemiptera: Cicadellidae: Coelidiinae: Teruliini). Revista de Biologia Tropical. 62: 1375-1383.

Puissant S. 2006. Contribution à la connaissance des cigales de France: géonémie et écologie des populations (Hemiptera, Cicadidae). Bédeilhac et Aynat, France: ASCETE, ASssociation pour la Caractérisation et l'ETude des Entomocénoses.

Puissant S, Sueur J. 2001. Contribution à l'étude des Cigales de Corse (Hemiptera, Cicadidae). Bulletin de la Société Entomologique de France. 106: 429-436.

Redak RA, Purcell AH, Lopes JRS, Blua MJ, Mizell III RF, Andersen PC. 2004. The biology of xylem fluid-feeding insect vectors of Xylella fastidiosa and their relation to disease epidemiology. Annual Review of Entomology. 49: 243-270.

Ribaut H. 1952. Homoptères Auchénorhynques. II. Jassidae. Paris: Fédération Française des Sociétés de Sciences Naturelles.

Saponari M, Loconsole G, Cornara D, Yokomi RK, De Stradis A, Boscia D, Bosco D, Martelli GP, Krugner R, Porcelli F. 2014. Infectivity and transmission of Xylella fastidiosa by Philaenus spumarius (Hemiptera: Aphrophoridae) in Apulia, Italy. Journal of Economic Entomology. 107: 1316-1319.

Seljak G. 2013. Hishimonus hamatus Kuoh (Hemiptera: Cicadellidae): a new alien leafhopper in Europe. Acta Entomologica Slovenica. 21: 123-130.

Trivellone V, Knop E, Turrini T, Andrey A, Humbert J-Y, Kunz G. 2015. New and remarkable leafhoppers and planthoppers (Hemiptera: Auchenorrhyncha) from Switzerland. Mitteilungen der Schweizerischen Entomologischen Gesellschaft. 88: 273-284. 
Wang M, Zhang Y, Bourgoin T. 2016. Planthopper family Issidae (Insecta: Hemiptera: Fulgoromorpha): linking molecular phylogeny with classification. Molecular Phylogenetics and Evolution. 105: 224-234.

Weintraub PG, Beanland L. 2006. Insect vectors of phytoplasmas. Annual Review of Entomology. 51: 91-111.

Yurtsever S. 2000. On the polymorphic meadow spittlebug, Philaenus spumarius (L.) (Homoptera: Cercopidae). Turkish Journal of Zoology. 24: 447-459. 
Table 1. List and abundance of the Auchenorrhyncha species (adults and larva) collected in the Ajaccio region. For each species, the number of specimens successfully sequenced and the BIN assigned by the BOLD systems are indicated (Bold: new BINs).

* : conspecific taxa ;** : larva partially misidentified - an undetermined number of larva of Synophropsis lauri corresponds to Placotettix taeniatifrons.

\begin{tabular}{|c|c|c|c|c|c|}
\hline Family & Species & $\begin{array}{c}\mathbf{N} \\
\text { Adults }\end{array}$ & $\begin{array}{c}\mathrm{N} \\
\text { Nymphs }\end{array}$ & $\begin{array}{l}\text { Specimen } \\
\text { sequenced }\end{array}$ & BIN \\
\hline Aphrophoridae & Aphrophora alni & 1 & - & 1 & BOLD:ADP5304 \\
\hline Aphrophoridae & Neophilaenus campestris & 7 & - & 2 & BOLD:ACP8461 \\
\hline Aphrophoridae & Philaenus spumarius & 294 & - & 5 & BOLD:AAB1850 \\
\hline Cicadelidae & Anoscopus assimilis & 2 & - & 2 & BOLD:ACD5842 \\
\hline Cicadelidae & Aphrodes makarovi & 6 & 30 & 1 & BOLD:ADE0937 \\
\hline Cicadelidae & Jikradia cf. olitoria & 1 & - & 0 & N/A \\
\hline Cicadelidae & Aconurella prolixa & 4 & - & 2 & BOLD:AAZ5698 \\
\hline Cicadelidae & Allygus modestus & 6 & 15 & 2 & BOLD:ACR1103 \\
\hline Cicadelidae & Anoplotettix fuscovenosus & 41 & 222 & 2 & BOLD:ADP1303 \\
\hline Cicadelidae & Balclutha frontalis & 16 & - & 2 & BOLD:AAD4769 \\
\hline Cicadelidae & Circulifer haematoceps & 17 & - & 2 & BOLD:ADO2697 \\
\hline Cicadelidae & Eupelix cuspidata & 4 & - & 2 & BOLD:ADN9562 \\
\hline Cicadelidae & Euscelis alsia & 12 & - & 2 & BOLD:ADN8776 \\
\hline Cicadelidae & Euscelis lineolata & 532 & 230 & 4 & BOLD:ACY0335 \\
\hline Cicadelidae & Exitianus capicola & 1 & - & 2 & BOLD:ACP7902 \\
\hline Cicadelidae & Goniagnathus guttulinervis & 4 & - & 1 & BOLD:ACP8518 \\
\hline Cicadelidae & Hishimonus hamatus & 1 & - & 1 & BOLD:ADT2006 \\
\hline Cicadelidae & Neoaliturus fenestratus & 1 & - & 2 & BOLD:ADP0308 \\
\hline Cicadelidae & Opsius stactogalus & 1 & - & 0 & N/A \\
\hline Cicadelidae & Orientus ishidae & 1 & - & 0 & N/A \\
\hline Cicadelidae & Phlepsius spinulosus & 3 & - & 2 & BOLD:ADO1967 \\
\hline Cicadelidae & Placotettix taeniatifrons & 27 & 4 & 2 & BOLD:ADI7221 \\
\hline Cicadelidae & Selenocephalus conspersus & 29 & 29 & 2 & BOLD:ADP0043 \\
\hline Cicadelidae & Synophropsis lauri & 67 & $79 * *$ & 2 & BOLD:ACR2360 \\
\hline Cicadelidae & Thamnotettix dilutior & 9 & 34 & 2 & BOLD:ACQ1394 \\
\hline
\end{tabular}




\begin{tabular}{|l|l|c|c|c|c|}
\hline Cicadelidae & Bugraia ocularis & 29 & 1 & 2 & BOLD:ADO9929 \\
\hline Cicadelidae & Eurymelini sp. & 1 & - & 1 & BOLD:ADP0191 \\
\hline Cicadelidae & Anaceratagallia ribauti & 2 & - & 3 & BOLD:ACP5684 \\
\hline Cicadelidae & Austroagallia sinuata & 5 & - & 0 & N/A \\
\hline Cicadelidae & Megophthalmus scabripennis & 2 & - & 2 & BOLD:ACS2510 \\
\hline Issidae & Agalmatium bilobum & 1 & - & 1 & BOLD:ADQ5346 \\
\hline Issidae & Agalmatium flavescens & 14 & - & 3 & BOLD:ADO2357 \\
\hline Issidae & Issus muscaeformis & 18 & 163 & 1 & BOLD:ADK5090 \\
\hline Issidae & Latilica maculipes & 180 & 391 & 2 & BOLD:ADJ2737 \\
\hline Tettigometridae & Tettigometra impressifrons & $2 *$ & - & 1 & BOLD:ADP2274 \\
\hline Tettigometridae & Tettigometra laeta & 2 & - & 0 & N/A \\
\hline Tettigometridae & Tettigometra sp. & $4 *$ & - & 4 & BOLD:ADP2274 \\
\hline Tettigometridae & Tettigometra virescens & 17 & - & 1 & N/A \\
\hline \multicolumn{1}{|c|}{ Total } & $\mathbf{1 3 6 4}$ & $\mathbf{1 1 9 8}$ & $\mathbf{6 6}$ & $\mathbf{3 1}$ \\
\hline
\end{tabular}


Figure 1. Intra- and inter-specific pairwise differences between the Auchenorrhyncha taxa used in this study. Groupings were generated from species identifications. Red box: inter-specific issue; Blue box: intra-specific issue; Green box: intra-specific potential issue.

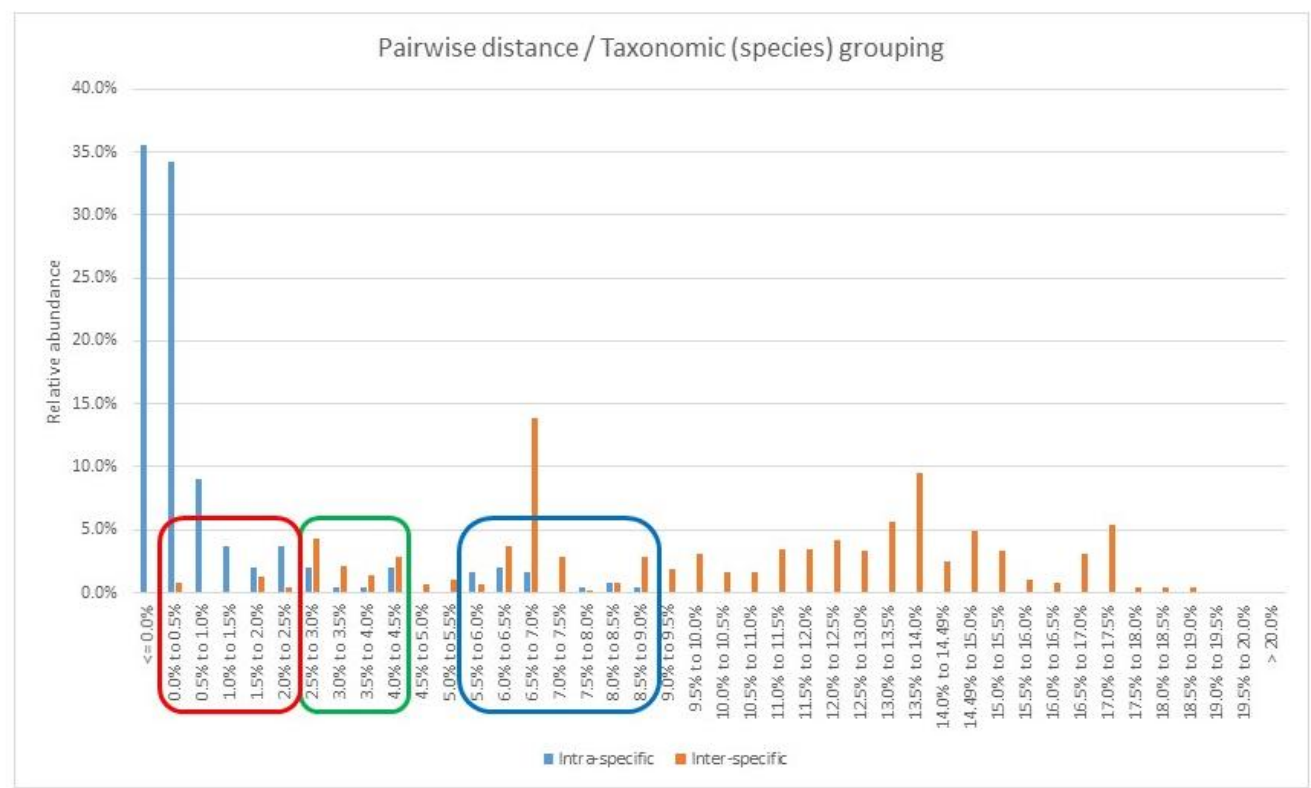

A. flavescens, A. bilobum, A. makarovi, H. phycitis, E. exitiosus A. albifrons group (albifrons, limicola, assimilis) $\square$ A. alni 
Figure 2. Auchenorrhyncha species (adults) collected during a one-year survey in the Ajaccio region. Euscelis lineolata, Philaenus spumarius and Latilica maculipes account for up to $74.3 \%$ of the total of the insect collected.

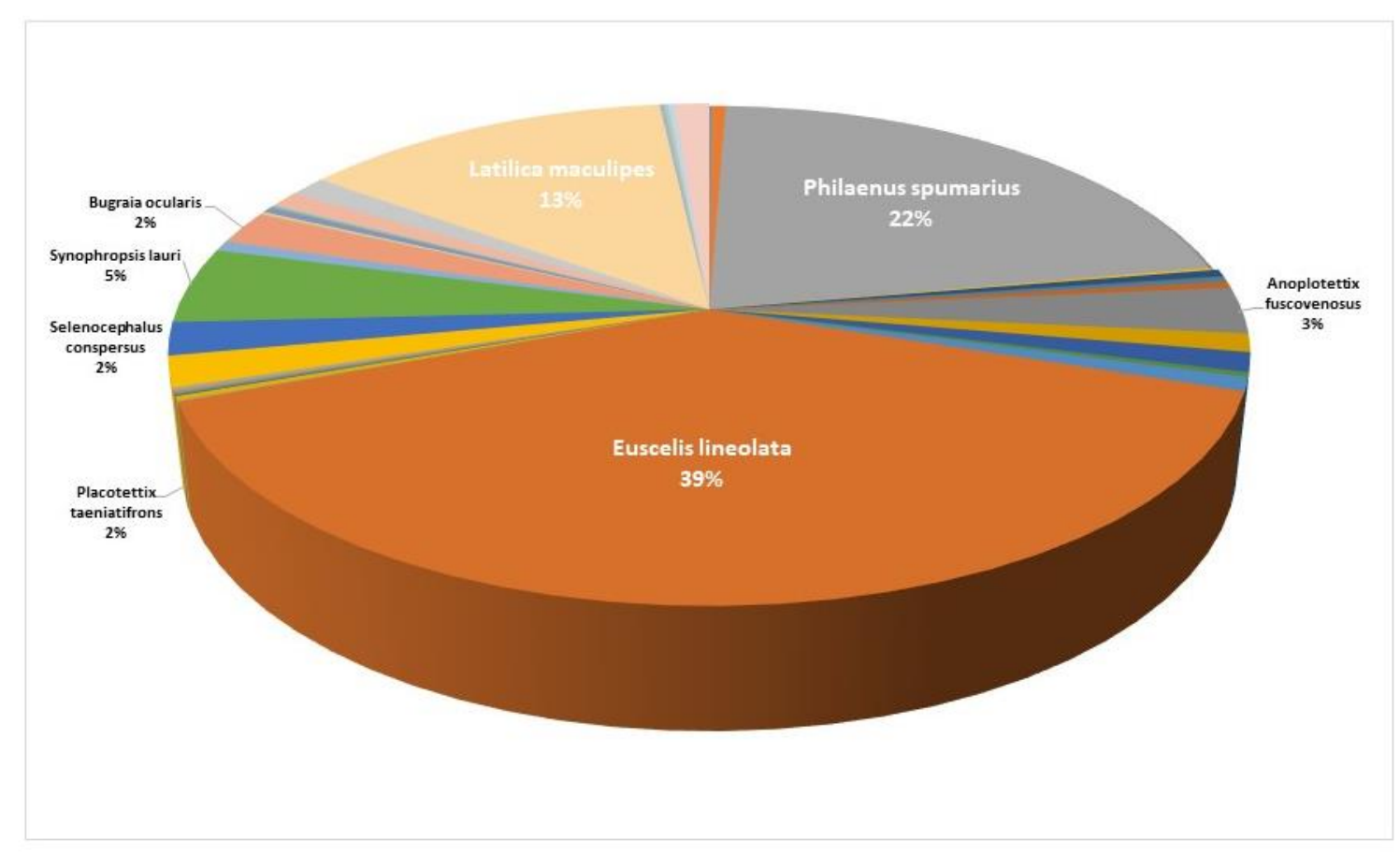


Figure 3. Monthly abundance of the main Auchenorrhyncha species collected in the Ajaccio region.

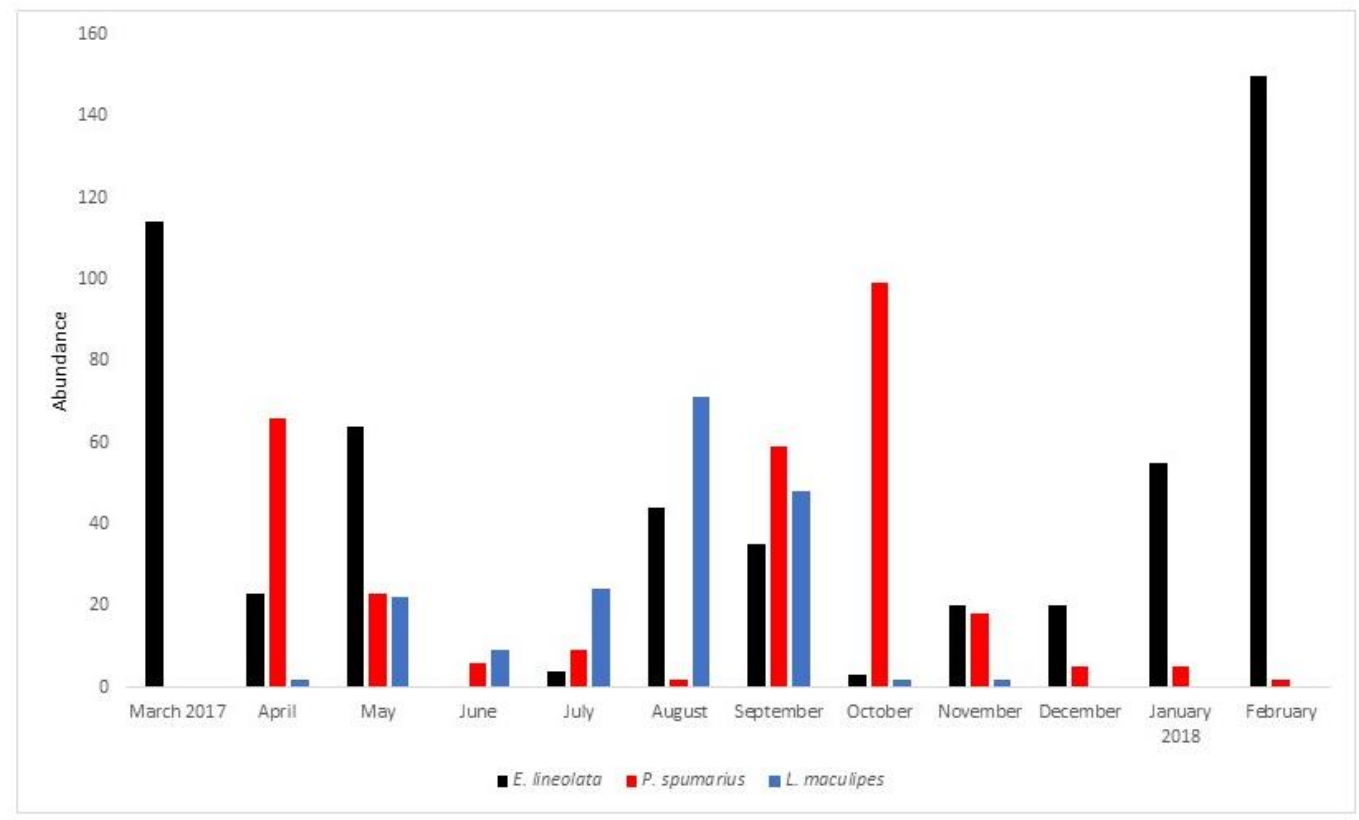

